\title{
EFICACIA Y EFECTIVIDAD DEL DERECHO
}

\author{
Manuel María Zorrilla Ruiz \\ Catedrático de la Universidad de Deusto \\ Profesor Visitante de la Universidad «Montesquieu» de Burdeos (Francia) \\ y de la Universidad de Łodz (Polonia)
}

\section{Perspectivas generales de la eficacia del Derecho}

La aptitud del Derecho para desencadenar las transformaciones que se esperan de la vigencia de sus normas, depende de la dosis de voluntad y de interés con que el poder público las hace cumplir y consuma satisfactoriamente sus efectos. El poder que así actúa, se conduce al modo de un poder-función que - al contrario de la desnudez del poderfuerza-física o de la compulsión desmedida que refleja su rostro diabólico- persigue objetivos morales y sociales, cuyo alcance y conservación prueban su eficacia, y se caracteriza por la tenacidad con que va en busca de ellos y por la energía con que, una vez logrados, los defiende.

Las expresiones del Derecho que tienen la naturaleza de normas jurídicas, se proponen servir al interés general o, lo que es lo mismo, facilitar el acceso de la sociedad al bien común que se traduce en el conjunto de exigencias de la coexistencia, de la colaboración y de la participación. Reflejo, todas ellas, de los frentes o espacios sociales en que se localizan los procesos de crecimiento individual y de desarrollo de los grupos de personas físicas que se integran en las comunidades respectivas.

El Derecho produce sus efectos gracias a la fuerza moral y el vigor lógico de los presupuestos intelectualistas - que prefieren un futuro basado en el decisionismo justo del legislador-o a la insistencia - fanática en ciertas ocasiones - con que las actitudes voluntaristas adoptan posiciones coyunturales o pragmáticas que no comulgan con la continuidad de las inspiraciones éticas.

El Derecho adquiere una virtud transformadora cuando sus esfuerzos de disuasión preventiva y corrección terapéutica no se disipan en 
pos de objetivos falsos o mal seleccionados, sino que fijan acertadamente las condiciones de generalidad con que se intenta responder a las demandas sociales significativas y dignas de atención. Esta pulcra tarea de racionalización - que, a primera vista, se desentiende de las cosas concretas y apuesta por vastos horizontes-incluye un ingrediente de eficacia, cuya tenacidad constructiva garantiza la calidad de las fórmulas a que se recurre para afrontar los problemas nacidos de los conflictos que el Derecho compone o trata de evitar.

La causa de un Derecho eficaz - llamado a confiar en la contribución valiosa de los moralistas a la faena existencial de su saludable formación- se ha visto entorpecida siempre por la incomunicación, irreversible e infeliz, que ha existido entre aquéllos y las comunidades de juristas. Alienados, los unos, en la fabricación simulada de una historia a cuyos episodios retadores han vuelto la espalda, no sin temer su proliferación y estar informados de su frecuencia abrumadora. Dedicados, los otros, a encontrar soluciones que, unas veces, contienen medidas de socialidad superficial y, otras, acusan un hipergarantismo de desolación y desgaste sociales, siempre indecisos ante la vocación de las razones éticas con las que no se identifican comprometidamente.

Las reacciones de la comunidad internacional son la demostración - escandalosa, cuando más, o desedificante, cuando menos- de la distancia que separa sus cuerpos morales de doctrina - auténtico depósito de las verdades del orden natural - del escaso fuste de las medidas ejecutivas que se adoptan, si llega el momento - pospuesto indefinidamente o aplazado demasiadas veces - de emprender las acciones jurídicas que reclaman los atentados contra la vida humana y la existencia de las comunidades.

El Derecho gana en eficacia porque, apoyándose en la indispensable solidaridad colectiva (art. $45.2 \mathrm{CE}$ ), intenta repartir, fuera de todo agravio comparativo, los bienes escasos en que consisten una libertad y una igualdad cuya síntesis - ni mezquinamente igualitaria ni desmesuradamente liberal- muestra la imagen de la justicia plena y no desfigurada que de antiguo se viene propugnando.

El Derecho es denostado por quienes sólo aciertan a ver en sus operaciones lo complejo y, a veces, esotérico de unos tecnicismos que, lejos de cualquier arbitrariedad, se explican por la necesidad de aunar los valores de la justicia y la seguridad jurídica (arts. 1.1 y $9.3 \mathrm{CE}$ ). El Derecho merece y recibe el elogio de cuantos le juzgan insustituible para promover, flexibilizar y acrecentar los vínculos entre los individuos y/o las comunidades. Si el Derecho gana en aceptación y prestigio, es porque sabe estar al servicio de los intereses generales que, en cada círcu- 
lo o sector de las sociedades pluralistas (art. 20.3 CE), reclaman el auxilio de las normas jurídicas que cuidan de esas exigencias. El Derecho impera merced a la coerción — que se atiene a criterios de sana posibilidad — de la autoridad — que se acata por razones múltiples, cuya definición y deslinde son harto difíciles - y a la aceptación reflexiva, todo lo contrario del buen obedecer, de los destinatarios de sus normas.

El Derecho obtiene resultados positivos en la medida que sus soluciones se adaptan a los criterios razonables que justifican la intervención coactiva de los poderes públicos. Para que así sea, el Estado social y democrático de Derecho - que se inspira en pautas de tecnificación jurídica y progreso social - necesita de los controles destinados a disuadir de las tentaciones de ejercicio abusivo del poder. Utiliza fórmulas que - como la censura jurisdiccional ordinaria de los actos del poder ejecutivo o la fiscalización de las decisiones inconstitucionales (arts. 106.1 y $161.1 a \mathrm{CE}$ ) - aquí y ahora pasan a ocupar el lugar del que, según un viejo postulado de la doctrina del orden natural, era el derecho histórico de resistencia frente a las demasías del poder injusto. La atenuación de las tentaciones totalitarias del Derecho no sólo obedece a las razones éticas que aconsejan ir detrás de sus pasos, sino también a las condiciones racionalizadoras que aparecen cuando el Derecho del Estado coexiste con uno o más ordenamientos jurídicos extraestatales y reclama un sistema de interrelaciones que garantiza su equilibrio mutuo.

El Derecho intensifica su eficacia cuando las conexiones del Estado-ordenamiento y el Estado-comunidad fomentan la prosperidad de sus reservas éticas y aumentan las oportunidades de ajustarse a estos imperativos. El Estado-comunidad — que procede de la conversión de las colectividades de origen en comunidades reflexivas y del advenimiento de éstas a otras formas de cooperación y convivencia más perfectas- esboza las líneas de fuerza de los proyectos sociales que el Derecho objetivo acoge, depura y asimila. El Estado-ordenamiento logra, a costa de las precisiones y reajustes que posibilitan la distensión normalizadora de los conflictos sociales, un óptimo de organización que armoniza la paz social —uno de los elementos de la noción tradicional de orden público - con la autonomía de los grupos que nacen y crecen en su seno (arts. 9.2 y 10.1 CE). El esfuerzo de transformación - debido a incentivos variables y superadores de las tentaciones de sometimiento o de rutina- revela cómo, más allá del concepto jurídico determinado de eficacia, interviene un concepto jurídico indeterminado de efectividad. La eficacia implica, entre otras acepciones, que el Derecho beneficia a cuantos ostentan la cualidad de portadores de un 
interés legítimo — signo de la utilidad o ventaja pretendida- que les introduce en la esfera protectora del ordenamiento jurídico. La efectividad significa que, sólo si hay verdaderas oportunidades de acceder a tales beneficios, el Derecho rinde un servicio auténtico a la comunidad y acredita su sincero propósito de tutela y de cambio. Cambio que no es, al uso civilístico de las obligaciones de medios o de simple actividad, un estéril y vano despliegue de energías, caracterizado por el predominio de lo testimonial o lo retórico, sino que exige la constancia - algo más y distinto de la añoranza o las predicciones optimistasde unas dosis de libertad y de igualdad que, sabia y serenamente ponderadas, arrojan un saldo de justicia. A medida que esta orientación gana terreno, se afianzan la buena voluntad y el optimismo de unos poderes sociales - inventores y protagonistas de la biografía del Estado-comunidad- a los que los poderes públicos transmiten un plus de regeneración que explica la razón de ser y, en su caso, el éxito de la revolución desde dentro. La revolución creadora de un Derecho eficaz se ha llamado razón sin historia, y la contrarrevolución —su hermana gemela - ha soportado el rótulo de historia sin razón. La revolución desde dentro consiste en innovar, sin merma de la sujeción de los pobres públicos al ordenamiento jurídico, los adelantos que demanda su voluntad transformadora.

\section{Eficacia del Derecho en el marco de las posibilidades y dimensiones del ordenamiento jurídico}

La acción transformada del Derecho es impensable sin la fuerza que emana del proceso creador emprendido por las colectividades inorgánicas y las comunidades primarias para acondicionar su futuro - todo un proyecto impregnado de perfección y de aventura- mediante los factores de racionalización que lo permiten. El Derecho - solución cultural que procede del concepto y funciones del ordenamiento jurídico- es la causa formal de las comunidades que, gracias a sus peculiares experiencias históricas, alcanzan el óptimo de organización que caracteriza al modelo del Estado social y democrático de Derecho (arts. 1.1 y 9.3 CE). No faltan posturas particularistas que - abundando en los excesos de los nacionalismos resurgidos o las torpezas de los fundamentalismos implacables - deterioran muchas de las adquisiciones logradas en este orden de cosas.

La máxima de que nunca es bueno ni saludable el cálculo de los egoístas, lo dice todo sobre las opciones del Derecho que aspiran a una eficaz aplicación de sus normas. Un Derecho moralmente devaluado 
- cuando es vano el intento de hallar en sus proposiciones un atisbo de sensibilidad ética- nunca será eficaz, porque le falta el mínimo del impulso preciso para subordinar las preferencias del legislador a los requerimientos del interés general y del bienestar individual. Sólo a corto plazo puede dar la impresión — que se esfuma en seguida - de un efímero triunfo y un no menos caduco reconocimiento. El crudo voluntarismo del legislador - plasmado en consignas y promesas de escaso fuste intelectual y moral - nunca va más allá de sus designios maximalistas o domésticos, por mucha publicidad o adorno demagógico que acompañe a sus experimentos. La grandeza moral —intuida y/o adivinada, sin esfuerzo, en las acciones y reacciones que verdaderamente la llevan consigo- no es sólo una condición cualitativa del Derecho que, para el buen fin de sus operaciones, necesita de las aportaciones éticas. Representa también, andando el tiempo, el mejor y más sólido aval de su eficacia. Hay, en el fondo de las cosas, cierto recelo o resistencia -individual y social- a consumir un Derecho de mala calidad que, cuando no se rechaza de entrada, se resiente, a la larga, de ese vicio y se ve abolido por la apatía o el desuso de sus destinatarios (arts. 2.2 y 3.1 C.c.).

El Derecho triunfa y culmina la lucha emprendida en pro de su causa y sus finalidades, si, además de acoger esas inspiraciones éticas, acomoda las normas jurídicas al pluralismo político o, más bien, a las múltiples expresiones que este valor -ideológicamente variable- adquiere con motivo de las operaciones de animación y población del ordenamiento jurídico (arts. 6 y 66.2 CE). El Estado social y democrático de Derecho deja, por definición, de ser tal, si su estructura peligra o se resiente ante una variedad de preferencias ideológicas, cuyas sucesiones o cambios, lejos de acarrear riesgo alguno para su subsistencia, deben conservar su excelencia juridicopolítica y convertirse en factores de regeneración y creatividad (arts. 1.1 y 9.3 CE).

Esos cambios acusan las variaciones naturales de la voluntad popular —en que reside originariamente la soberanía política (art. 1.2 CE) - y aportan un dato de ponderación que permite conservar un equilibrio indispensable. Los individuos y grupos intermedios imponen sus predilecciones cuando, en virtud de los procesos de actuación parlamentaria, las mayorías reflejan el mensaje vinculante de esa voluntad y las minorías defienden, a su vez, que la eventual dominación de las primeras no puede suplantar sus determinaciones ni secuestrar sus derechos individuales y colectivos (arts. 68.1 y 69.1 CE). Ello es así porque, sin desdibujar los rasgos permanentes del Estado social y democrático de Derecho, está fluyendo siempre - con la ductilidad característica de su incesante retorno- un orden natural de contenido variable que, respetando axiomáticamente las que nunca han dejado de 
constituir sus verdades centrales, evoluciona al ritmo de un espíritu móvil que facilita la adopción existencial de las soluciones convenientes a cada circunstancia de tiempo y de lugar. Hay una suerte de obligación de atención y cuidado que tiene por objeto asegurar el éxito de estos objetivos.

El vigor del Derecho se refleja en las garantías que su aplicación extrae de la síntesis de los valores de la justicia y la seguridad jurídica. El examen de las decisiones de los jueces, en particular, y, en general, el análisis de las operaciones de aplicación del Derecho, muestran que esa eficacia está favorecida por la propensión - discreta, en un principio, y creciente después- a mitigar el rigor de los preceptos positivos e incluso de las ataduras del sistema de fuentes (art. 1.1 C.c.). Esta eficacia del Derecho reclama un uso evolutivo o divergente que asume sus responsabilidades cuando han quedado atrás la coyuntura histórica y la oportunidad del que fue novedoso ejercicio del uso alternativo del Derecho. El Derecho eficaz - cuyos modos de aplicación siguen expuestos a la seducción del pluralismo político y a los toques de atención del orden natural - puede alejarse, pese a la servidumbre y el pie forzado del sistema de fuentes (art. 1.6 C.c.), de las formas rígidas de un Derecho de preceptos y convertirse en un Derecho de principios que apuesta por un sugestivo porvenir. De este futuro forman parte la simplificación del aparato normativo, la espiritualización lineal de los mensajes del legislador y el recurso - propio del uso constitucional del Derecho- cada vez más frecuente a los principios y/o preceptos de la legalidad fundamental. Se condesciende así con soluciones que -emanadas de la justicia constitucional y de los jueces ordinarios- parecen menos complementarias del elemento normativo y más reveladoras de una costumbre judicial, pues, lejos de resignarse a ser el eco de las palabras de las leyes, las sustituyen y transforman para actualizarlas saludablemente. La sumisión exclusiva al imperio de las normas constitucionales y ordinarias (art. 117.1 CE) es uso y aprovechamiento de las oportunidades que el ordenamiento jurídico brinda para reemplazar, a título corrector y no sólo interpretativo, el contenido - siempre inteligible e inequívoco- de unas reglas de Derecho en vez de las cuales se aplican los principios resultantes de su reconversión. Principios que, sobrepasando su identidad con esas normas, las reformulan en función de la finalidad y espíritu novísimos que les comunican las realidades sociales del tiempo y del lugar, a las que debe atenderse fundamentalmente (art. 3.1 C.c.), evitando toda consideración o referencia que debilite el vigor de este interesante discurso.

La penetración de las regulaciones jurídicas en los ámbitos de la vida social se debe al celo y diligencia con que los poderes públicos 
cuidan de ordenar sus más importantes aspectos, no tanto para invadir esos espacios por derecho de conquista, cuanto para atisbar los horizontes abiertos al aliento y el ejercicio de las libertades. El Derecho es doblemente eficaz, porque, de una parte, confiesa el propósito de sus regulaciones y, de otra, invita al compromiso de transformación inseparable de cualquier proyecto solvente de progreso individual y social (art. 9.2 y cap. $3 .^{\circ}$, tít. I CE). La eficacia del Derecho desborda el juego de las operaciones lógicas en que se alienan los juristas propensos a rehuir los desafíos de las realidades sociales cuya complejidad empaña la transparencia y — ¿cómo no?supera el simplismo del pensamiento deductivo, y excita a la aventura de la busca del Derecho justo. No basta que, usando de este pretexto aséptico e interponiendo la premisa menor de la pequeña historia, se llegue a la conclusión de un silogismo en que la ley, la costumbre, y los principios generales del Derecho han estampado - como elemento jurídico que individualiza la causa de pedir identificadora de la acción - la premisa mayor de ese discurso. A la hora de acondicionar las relaciones humanas, el Derecho no elude las dificultades de semejante empresa y, para superarlas, inventa - es decir, descubre razonablemente - soluciones que van integrando iniciativas expresas y tácitas, conscientes e inconscientes, predeterminadas y difusas. Todas ellas componen una síntesis de intelección y de emoción que no se reduce a la visión instantánea que exige la tarea de los aplicadores del Derecho. Coinciden en la medida común de la eficacia que esos protagonistas juzgan imprescindible para defender intereses legítimos de fisonomía y espectro variables. El enigma de la construcción del Derecho obliga a operaciones numerosas de distensión y ajuste, sin cuya intervención y auxilio - fruto, no pocas veces, del reflejo intuitivo o la feliz idea- la eficacia de las normas jurídicas se frustra o está en tela de juicio.

La eficacia del Derecho se predica también de su aptitud para administrar - mitigándolas en lo posible - las tensiones que caracterizan a los conflictos sociales. Su tratamiento no consiste en liquidarlos apresuradamente con arbitrios que se precipitan a presumir la bondad de las acciones individuales, pero que, a cambio, no computan las $d o-$ sis de flaqueza de la condición humana. El Derecho no puede imponer, so pena de fracaso y descrédito, comportamientos o reacciones cuya imposibilidad o extraordinaria dificultad de ejecución lleve a incurrir, por exceso o defecto, en el grave pecado de la desesperación civil. La idea prosaica de que lo mejor es enemigo de lo bueno, cuenta a la hora de condescender equitativa y razonablemente con el dato de los desfallecimientos que debilitan el ejercicio de las potencias del alma. 


\section{Eficacia técnica de las soluciones del Derecho}

La calidad y eficacia del Derecho dependen del cuanto de animación política que, en función de unas u otras opciones ideológicas, inspira los procesos de ideación y creación de las normas jurídicas. La elevación del pluralismo político al rango de valor superior del ordenamiento jurídico (art. 1.1 CE) significa que, aceptando los riesgos de los imponderables y/o sorpresas de esta postura novedosa, el Derecho objetivo se mantiene fiel a su consigna de permanecer y asegurar la aplicación — satisfactoria y duradera - de sus normas. El peso del pluralismo político no es un factor anómalo que ahuyenta, desorienta o desintegra, sino que facilita el hallazgo de nuevas fórmulas de síntesis, al mostrar la importancia de las aportaciones cuya fisonomía explica la contribución central que los ensayos creadores del Derecho reciben de los agentes políticos responsables de sus iniciativas. Reducir esta fecunda posibilidad a un monismo inservible y empobrecedor, es fomentar un fundamentalismo encubierto que no siempre cae en la cuenta de la antisocialidad de su proyecto.

A la calidad y eficacia del Derecho cooperan la correlación y consecuencia de las normas jurídicas con las orientaciones de la Historia, cuyos episodios ejemplifican el ejercicio del don del consejo en punto a la acogida o la repulsa de las soluciones que se miran en el espejo de sus experiencias. El Derecho objetivo comulga, así las cosas, con las enseñanzas históricas que le instruyen y ayudan a descifrar los signos de los tiempos. El pasado no ha quedado atrás solamente para imprimir al Derecho la nota de evocación o de nostalgia que se desinteresa de sus necesidades de eficacia, sino también para que los participantes en los procesos de perfección jurídica sepan de los aciertos que, a causa de ese aprendizaje, hay que reconocer y asimilar, y de las experiencias positivas que, liberando del error, abren los caminos de la verdad. Los testimonios de la Historia arrojan luz sobre las empresas de reforma social que incluyen operaciones de creación y redefinición legislativas. Dan cuenta, con lucidez abrumadora, de los datos que, según las circunstancias, son decisivos para reaccionar en clave de optimismo, de decepción o de escarmiento. La Historia registra los fenómenos de inutilización de las normas jurídicas - neutralizadas por el desuso o abolidas por las realidades sociales que, al fin, pierden su capacidad de actualizarlas-e insinúa las alternativas con que cabe renovarlas o sustituirlas. La Historia levanta también acta de las peripecias en que el Derecho - cuya eficacia se reclama - resulta imprescindible. La Historia es, en fin, una obra dramática cuya puesta en escena se ensaya y se repite en todas las tentativas ulteriores de análisis y de comparación. 
La calidad y eficacia del Derecho mejoran cuando, al dar un paso adelante, la llamada legislación en sentido material o vertical (art. 149.1 núms. $6 .^{\circ}$ a $9 .^{\circ}, 12 .^{\circ}, 18 .^{\circ}$ y $22 .^{\circ} \mathrm{CE}$ ) accede a los espacios no regulados hasta entonces por las normas jurídicas escritas y penetra en ellos para desplazar a las fuentes secundarias que evitan la formación de las llamadas lagunas del Derecho (art. 1.1 a 3 C.c. y $§ 8$ EMTPC.c.). Resta por estar cierto de si un Derecho objetivo que se entrega a operaciones de regulación exhaustiva, es más eficaz que un Derecho cuya sobriedad normativa genera y/o agranda otro fenómeno. El de la emergencia de ordenamientos jurídicos extraestatales que, aduciendo necesidades de eficiencia y subsidiariedad, se ocupan de aquellos conflictos que razones de origen muy vario - abundancia de cláusulas convencionales, exigencia de conocimientos técnicos especializados y/o inconvenientes de demora - aconsejan sustraer a la intervención de los poderes públicos. La demora del legislador justifica el voto de castigo que le recuerda el deber diligente de crear un Derecho apto para el remedio de esas situaciones, o que, ante el éxito de las alternativas de sustitución, le disuade de agotar semejante propósito y le permite entregarse a otras atenciones.

Un Derecho pretendidamente eficaz tiene que elegir sabiamente los objetivos de las acciones reguladoras que pretende llevar al mejor de los fines. Esta virtud depende de su acierto en el diagnóstico de las necesidades apreciables para satisfacerlas. No deja de ser sorprendente y paradójico que, aunque la posesión de las libertades pertenece a la intimidad de la persona y escapa al control de los sentidos, su dependencia de la realidad cosmológica las configura como bienes que, al adquirirse y disfrutarse en condiciones de colimitación y escasez, ocupan lugar y requieren un equitativo reparto. La eficacia del Derecho se mide también por el tino de que hace gala al regular los intereses —apetencia o afán de la utilidad o beneficio que cada sujeto individual o colectivo obtiene del goce de una situación a cuyo disfrute no renuncia- que la persona defiende, en cada caso, como parte del acervo de sus bienes de vida. El Derecho no puede permitirse la licencia de incurrir en error sustancial al realizar la elección de los bienes y valores cuyo régimen de reparto satisface alguno de los intereses generales confiados a la competencia normativa y el acierto técnico del legislador. Un bien es, en sentido amplio, la parte de la realidad, absoluta o relativamente sensible, que gratifica y acrecienta las expectativas de quienes cuentan con su contribución y, andando el tiempo, la juzgan indispensable para asegurar el cuanto de utilidad a que se aspira. Alguna relación guarda ello con la ley del crecimiento rítmico de las necesidades. El valor constituye un bien inmaterial cuya utilidad se percibe mediante la comprensión y la emoción, al sintetizar la concepción natural 
de lo que significa y la espontánea inclinación que su aliciente está causando. Cada sector del ordenamiento jurídico que se precia de eficacia social, debe regular - por razones de propensión individual y de escasez- la suerte de los intereses comprendidos en el círculo de bienes $y$ derechos subjetivos que el Derecho objetivo cuida de elegir y ordenar con alguna racionalidad.

La eficacia del Derecho es también obra de las preferencias - razonables y no descabelladas - de los destinatarios que propugnan unas $\mathrm{u}$ otras de las soluciones que se les debe deparar. El Derecho no puede salir al mercado como quién sabe qué bien perecedero cuya oferta se supedita a lo frívolo y veleidoso de la moda. Vicio de que adolecen las promesas y consignas radicales de los modos de actuar propios del voluntarismo político, pues, a la larga, es deplorable que la política legislativa no acierte a trazar la línea de mínima continuidad y continencia, compatible con los giros - discretos y no copernicanos- de las orientaciones ideológicas que penetran en la legislación. La evaporación rápida de las soluciones del Derecho deja de ser un mérito si, en favor de otra u otras comunidades o grupos, una parte del cuerpo social se ve destituida de las ventajas legítimas y razonables que el legislador le ha procurado. Uno de los aspectos criticables de la soberanía de la ley es la negación de la garantía expropiatoria frente a las disposiciones legislativas de carácter general (arts. 33.3 y 67.1 CE). Una de las servidumbres y grandezas del Derecho - porque haberlas, las hay y de fisonomía variopinta - es la síntesis de su pretensión de modernidad y del componente conservador de las soluciones en que abunda. La eficacia del Derecho dimana, en este punto, de combinar un principio doctrinal de continuidad con una regla histórica de progreso. El ritmo deseable de perfección para el Estado social y democrático de Derecho, presupone el normal ejercicio de los poderes públicos y, llegado el caso, la adopción de iniciativas que animan y completan los episodios descriptivos de la revolución desde dentro (arts. 9.2 y 10.1 CE). La elasticidad históricoevolutiva resulta decisiva para asegurar ese delicado equilibrio, porque el Derecho es, a la vez, igual a sí mismo y exponente de las demandas de un cambio que, sin merma de sus identidades, debe ocurrir sin pausas ni demoras. La eficacia del Derecho resalta la susceptibilidad de un uso provechoso que, lejos de reducir las normas jurídicas al marco de un mensaje caduco a corto plazo, extrae de ellas las propuestas flexibles que agilizan, mejoran o enmiendan la estrechez y el rigor de sus propuestas originalistas. Toda norma dúctil acoge la voluntad que fluye de un legislador que — si sabe actuar prudentemente y no cegado por su obsesión de omnipotencia - se adelanta a los inconvenientes de una voluntad inmovilista que no es del momento. Deja de 
refugiarse en las motivaciones elementales de la ley y, desde su nacimiento, le transmite - como conviene a la obra bien hecha - la capacidad de adaptación que las tesis del originalismo a ultranza proscriben por sistema. Un legislador sensible a estos aspectos cuida de que la norma jurídica contenga los elementos de flexibilidad que facilitan los ejercicios de su interpretación correctora, liquidando los entorpecimientos del inmovilismo estéril que se resiente de todos los vicios de la letra que mata, y no posee ninguna de las virtudes del espíritu que vivifica.

Es insincero y falso el prejuicio de que la eficacia del Derecho está en razón directa de su respuesta y fidelidad incondicionales a las demandas sociales que reclaman su intervención en cada caso. Muchas de ellas no se recatan en exhibir un rostro aberrante que les priva de la razonabilidad elemental y condena a muerte jurídica sus pretensiones de protección legislativa. El análisis legislativo de un problema de interés general se considera justo, si la opinión pública — que ha de ser informada y activa, como reza una regla ya clásica, y nunca incurrir en el defecto de mostrarse desorientada o apática - está rotundamente convencida de que la solución deseable no puede aplazarse sin riesgo de dañar gravemente los intereses de las personas o grupos afectados. Hay razones de peso para defender que una demanda social no es justa, si la opinión pública entiende que la demora en atenderla no crea un riesgo grave de inestabilidad para los intereses en juego, ni produce suerte alguna de alarma social. El legislador debe probar que la ley puesta en la ciudad cuenta con vocación y probabilidades de eficacia, y que no se reduce a ser el eco de previsiones intemporales, frivolidades políticas o circunstancias que la destituyen del valor vital que ha de acompañarla en todo tiempo.

Un aspecto central de la eficacia del Derecho es el cumplimiento de las misiones que le incumben en punto al tratamiento de los conflictos sociales. El ordenamiento jurídico reacciona en función de la fuerza creadora y del ímpetu transformador de los distintos hechos conflictivos. Hay conflictos sociales privativos de grupos apáticos, a los que el Derecho ayuda en la medida necesaria para regenerar las libertades que no aciertan a promover, si bien, a causa de esta insuficiencia, el legislador regula no pocas de sus peripecias y suple las omisiones de sus protagonistas. Hay conflictos sociales de vibración ponderada, a los que los sectores del ordenamiento jurídico en que surgen y se desarrollan, no pierden de vista ni, por decirlo así, dejan de la mano. Hay, en fin, conflictos de dinámica torrencial, cuya autonomía y ansias de libertad les hacen inmunes a cualquier esfuerzo de regulación jurídica, e incluso llevan a abolir el Derecho constituido. La eficacia del Derecho difiere en unos y otros. El conflicto social no 
está llamado — salvo si la exageración febril de sus tensiones degrada o disuelve toda o una parte de la sociedad en que se localiza- a disiparse, sino a prevalecer como clave de la liberación de los grupos y de las personas integradas en éstos (art. 9.2 CE). Son otros los rasgos distintivos del conflicto individual, que pertenece a la patología de las relaciones humanas, que viola la consigna de que se puede y se debe vivir en paz con todos, si así se lo proponen y tratan de lograrlo la recta intención y la buena voluntad de cada uno, y que espera del Derecho el paliativo de los males que, sin mérito alguno para la causa de lo bueno, se siguen comúnmente de su enrarecimiento.

La eficacia del Derecho depende también de la medida en que las normas de orden público cumplen, más o menos enérgicamente, sus cometidos de rectificación y garantía. El Derecho no puede abstenerse de limitar, llegado el caso, ciertas expansiones de la libertad, porque sólo se vive en dignidad cuando la idea de que el ejercicio de las libertades - escasas y necesitadas de un reparto justo-ocupa lugar, se cohonesta con la de que el Derecho puede y debe sentar las condiciones básicas que procuren esa distribución. La eficacia de las normas de orden público admite dos intensidades, según que prepondere la concepción liberal o prime la configuración autoritaria de sus regulaciones.

La eficacia del Derecho es incompleta, si la atención no se detiene en las reacciones y efectos que se siguen de sus perspectivas económicas. Una de ellas es la prioridad que, al adoptar una decisión legislativa, se fija en función del que cabe llamar coste de inversión económica de la norma jurídica. Algunas de éstas obedecen ciegamente las consignas de la voluntad política, imponen, sin prudencia ni pausa, sus predilecciones y constituyen, desde el punto de vista económico, una inversión infeliz e irrecomendable (arts. 31.2 y 128.1 CE). Hay leyes cuya eficacia no requiere el concurso de auxilios económicos, porque los intereses generales - a que, en su caso, atienden- se satisfacen con actos específicos o abstenciones de los poderes públicos, mientras que otras leyes sugieren proyectos inviables sin los medios de financiación que necesitan (cap. $3 .^{\circ}$, tít. I CE). Las leyes quedan abolidas si su inadecuación a las realidades económicas - parte integrante de las realidades sociales - impide utilizar éstas como elementos de interpretación que hacen posible la sobrevivencia y, en su caso, la reformulación de la norma jurídica (art. 3.1 C.c.). La eficacia del Derecho decae si sus destinatarios actúan en clave de entendimiento económico y, tras las oportunas previsiones, concluyen en favor de la productividad de la desobediencia, porque la utilidad material, derivada de desatender sus mandatos y prohibiciones, compensa lo ingrato y oneroso de los efectos sancionadores a que el incumplimiento da lugar. 
El Derecho es eficaz cuantas veces la prueba del supuesto de hecho de las normas jurídicas facilita la producción de los efectos que establecen. Lo contrario es ineficacia, desuso o abolición de las normas jurídicas que lo integran (arts. 2.2 y 3.1 C.c.). El Derecho es efectivo si su eficacia se eleva a la segunda potencia, porque sus resultados no sólo se dan en la medida autorizada por la iniciativa de los particulares o la coyuntura económicasocial, sino que dependen del ritmo de aceleración de la acción transformadora de los poderes públicos (art. 9.2 $\mathrm{CE})$. De ahí lo imperioso de poner fin a las discriminaciones y depresiones llamativas, y alienarse sin tregua en esas operaciones de progreso y de cambio.

El Derecho es eficaz por excelencia, cuando la voluntad general de la ley se traduce en la voluntad concreta de las sentencias judiciales que llevan a cabo su mandato. La protección jurisdiccional es efectiva, porque, respondiendo a una variante del derecho fundamental de petición (arts. 24.1 y 29 CE), satisface la singularidad de su ejercicio ante jueces independientes, responsables y sometidos exclusivamente al imperio de la ley (art. 117.1 CE). Hay, así las cosas, efectividad, porque la síntesis del valor superior de la justicia y del favor de la seguridad jurídica (arts. 1.1 y $9.3 \mathrm{CE}$ ) exige que, huyendo de lo superficial o dilatorio, la decisión judicial dilucide, de una vez por todas, el conflicto que enfrenta a los interesados. El respeto debido a la dignidad de la persona — que deriva de una existencia acorde con la inviolabilidad de los derechos que le son inherentes (art. 10.1 CE) - explica que la efectividad del Derecho incluya un poder de persuasión intelectual que no viene de la imposición del Estado para resolver el conflicto pendiente, sino del imperio de la ley que obliga a manejar criterios razonables y exentos de arbitrariedad.

\section{Variantes de la eficacia del Derecho en la esfera juridicopolítica}

La eficacia de un ordenamiento jurídico ha dependido, algunas veces, de la necesidad y el compromiso históricos de superar las experiencias de un sistema de Derecho estatal al que sucede otro que se constituye en virtud de un cambio político de reforma pacífica o de ruptura traumática. La instalación del nuevo Derecho eficaz - al que sus protagonistas atribuyen efectos socialmente positivos- puede ser fruto de una eficacia convulsiva, de una eficacia regresiva, de una eficacia nostálgica y de una eficacia reconstituyente. Todos ellos tienen de común la pretensión de erigir un Derecho que mejora las condiciones del estado jurídico de cosas que le ha precedido. 
El Derecho adquiere eficacia convulsiva merced a la experiencia revolucionaria que se da cuando, para poner fin a la inestabilidad y/o la ilegitimidad de un sistema, una o más minorías — que se adjudican la representatividad del cuerpo social- movilizan al pueblo que derroca violentamente el sistema establecido. El concepto clásico de revolución convive con la especie de la revolución institucionalizada o revolución desde dentro - distinta de la simple reforma y tan radical y agresiva como la revolución misma- que, a la larga, goza de alguna tradición histórica (arts. 3, 27, 123 y $130 \mathrm{CM}$ ) e inspira soluciones constitucionales que, andando el tiempo, no han consumado los cambios sustanciales a que obedecía su propósito. La eficacia revolucionaria del Derecho puede mudar un modelo cultural e inaugurar un ciclo histórico (arts. 1 a 6 DDHC), transformar notablemente la sociedad (arts. 3 II CI y 9.2 CE) o modificar la estructura del Estado creador del Derecho cuya excelencia se propugna (Pr. $\mathrm{CN}$ ).

La eficacia regresiva del Derecho surge si, a causa de objeciones distintas de las relativas a la inestabilidad o ilegitimidad de un sistema, una minoría carente de representatividad invoca otros valores o arguye pretextos que movilizan poderes de hecho extraños a la voluntad y participación populares — situadas al margen de estos movimientos- para perfeccionar las operaciones típicas de un golpe de Estado y abatir el poder constituido. Mientras que la eficacia del Derecho nacido de la revolución pertenece al proyecto de los agentes revolucionarios, los efectos jurídicos del golpe de Estado son imprevisibles y abocan a formas degeneradas o inauténticas de estabilidad.

La eficacia nostálgica del Derecho reacciona, al modo de denuncia, contra la frustración de los designios de regeneración asumidos por la revolución o, menos frecuentemente, por el golpe de Estado. La regresión que sobreviene a consecuencia de ello, apela al desengaño de esas soluciones y restaura el Derecho estérilmente sustituido por el que procedía de la eficacia revolucionaria o la eficacia regresiva de su acervo de normas jurídicas.

La eficacia reconstituyente del Derecho aparece cuando el marco fundamental sufre una revisión que actualiza los supuestos inspiradores del Derecho eficaz anterior. El carácter de la operación depende de las facilidades que, según la naturaleza rígida o elástica de sus regulaciones respectivas, ofrecen los procedimientos de reforma constitucional. Cabe incluso las opciones de revisión informal que emanan de la riqueza de oportunidades que depara el valor superior del pluralismo político (art. 1.1 CE). La indeterminación de no pocos conceptos y proposiciones jurídicas concede un amplio margen de maniobra 
para ensayar cambios de rumbo legislativos que se logran mejor intentando nuevas interpretaciones de las normas constitucionales flexibles, que a través de una revisión modificativa que no es indispensable para reducir las incompatibilidades e intransigencias ideológicas (tít. X CE).

Las opciones constitucionales - dirigidas, por definición, a instituir y fomentar un Derecho eficaz- descansan en tres proposiciones notables. La primera formula un elogio de la tolerancia, virtud civil por excelencia, que, de una parte, implica la renuncia a exigir de los demás el acatamiento de las propias ideas, y, de otra, justifica la oposición de la resistencia más enérgica frente a cualquier tentativa exterior de sofocar las libertades individuales y colectivas. La tolerancia se asocia a la promoción de la igualdad - acceso a las opciones compartidas por cuantos proclaman su voluntad de ser libres - y de la libertad, como ausencia de trabas a la iniciativa creadora de las personas y comunidades en cuya igualación se persevera. La actitud tolerante se sitúa en la cosmovisión de este horizonte, estimula sus posibilidades y se congratula de sus éxitos.

La segunda idea resalta el predominio del Estado-Comunidad sobre el Estado-ordenamiento, cuyo aparato debe ir cediendo su protagonismo a las personas y grupos sociales que forman el primero, de suerte que el Derecho anime y robustezca sus iniciativas, sin limitarse a sanar o suplir sus actitudes de indiferencia o apatía. De ahí el incremento y arraigo de los poderes sociales que llegan a crear ordenamientos jurídicos extraestatales o paralelos, cuya eficacia desafía y compite con la del Derecho del Estado (arts. 9.2, 20.3 y 37.1 CE).

La tercera idea concierne a la devaluación del concepto de soberanía, que interiormente se refleja en las variantes de descentralización políticoadministrativa - basadas en un principio de subsidiariedad o de eficacia (arts. 2, 103.1 y $137 \mathrm{CE}$ ) — y que exteriormente se traduce en cesiones o limitaciones que afectan a dicho atributo del Estado (arts. 93 y $94 \mathrm{CE})$.

Los poderes del Estado o de la mayoría política que refleja y expresa legítimamente la voluntad general (art. 1.2 CE), se morigeran gracias al testimonio de la eficacia del Derecho objetivo que suponen los derechos subjetivos constitucionales cuya inviolabilidad se pone de relieve (art. 10.1 CE). Derechos que, a causa de su efecto inmediato y sin perjuicio de sus variantes de desenvoltura, pertenecen al acervo del Derecho positivo (art. 53.1 CE) y se garantizan por las vías de efectiva tutela judicial que representan las acciones de la justicia constitucional y de la jurisdicción ordinaria (arts. 24.1, 53.1 CE y 161.1 $a$ CE). Sobre estos derechos gravita axiológicamente el haz de los valores superiores 
del ordenamiento jurídico, comprometido con el componente de moralidad legalizada que, una vez más, acredita el retorno incesante del cuerpo de doctrina del orden natural (art. 1.1 CE). Tales valores exigen que los poderes públicos - llamados a preservar la igualdad y la libertad en que se resume la justicia- cumplan la obligación natural —dependiente de su iniciativa y privada de la pretensión que la convierta en jurídicamente exigible- de alcanzar las condiciones óptimas que lo posibilitan.

El recurso a las normas de Derecho de Gentes (art. 10.2 CE) facilita la interpretación e integración de la parte de los derechos constitucionales que proceden del acervo de principios del orden natural y que se denominan derechos fundamentales y libertades públicas (sec. 1. ${ }^{\mathrm{a}}$, cap. 2. $^{\circ}$, tít. $1 \mathrm{CE}$ ). Sus normas adquieren la virtud inmediata o eficacia preceptiva directa que, con independencia de la movilidad de las opciones del desarrollo legislativo, producen desde ya las consecuencias anunciadas y — como parte de su contenido esencial o núcleo invulnerable - comprenden facultades que, sin necesidad de interposición del legislador, les protegen, ante la jurisdicción ordinaria, por vía de acción o de excepción (arts. 53.1 CE y 5.3 LOPJ).

La eficacia del Derecho no es dable sin el respeto máximo que reclama la idea absoluta de la dignidad de la persona (art. 10.1 CE), amparada mediante una disposición armónica de los valores del ordenamiento jurídico - sobreviviendo todos y cada uno de los mismos, y asegurando que los de orden superior prevalezcan sobre los de rango inferior-y del servicio que la causa de los derechos y libertades espera y exige de su contribución. Estos se justifican por su aptitud para coordinar aquella dignidad - supremacía de la persona sobre el resto de los seres que pueblan el mundo y se le subordinan- con el crecimiento que toma de ella su razón de ser y sus expectativas.

La eficacia del Derecho destinado a tutelar la dignidad de cada uno, justifica la pertinencia de un enjuiciamiento que, además de permitir el ejercicio del control general de la inconstitucionalidad de las leyes, otorgue a la justicia constitucional y a la jurisdicción ordinaria el poder de sancionar la vulneración de los derechos fundamentales y las libertades públicas por los poderes públicos y los particulares (arts. $53.2 \mathrm{y}$ $161.1 b \mathrm{CE}$ ). La eficacia del Derecho tanto está en la creación y consolidación de las obras del Estado-aparato, cuanto en el arraigo del sistema de valores que protege la dignidad del sujeto individual. Cuestión secundaria, aunque no exenta de interés, es la de si estos valores residen en el interior del ordenamiento jurídico —ocupando una posición eminente y superior a la de la norma fundamental — o si, situados fuera de él, imprimen carácter y se comunican a las experiencias de la aplica- 
ción e/o interpretación de su depósito (art. 1.1 CE). Se pregunta si, como presupuesto de la eficacia del Derecho, la instalación y acogida del sistema de valores constituye, a causa de su naturaleza, una limitación que se impone a la voluntad popular y proscribe cualquier intento de revisión constitucional que la contradiga o debilite. Los valores superiores del ordenamiento jurídico priman sobre los designios de la comunidad y de los poderes del Estado que emanan del pueblo. No son sólo superiores a causa de su preponderancia o virtud informadora del resto del Derecho objetivo, sino también de su prevalencia sobre la voluntad del pueblo soberano, cuyos representantes carecen de un poder juridicopolítico que les autorice a disponer de ellos y desnaturalizar las consecuencias axiológicas de su impacto. Frente a la tentativa de revisar el pasaje constitucional que implanta un sistema de preferencias moralizadoras, el valor superior del pluralismo político - invocado en pro de las interpretaciones alternativas de que, según las respectivas predilecciones ideológicas, incompatibles entre sí, son susceptibles los principios y preceptos constitucionales - con la prohibición de alterar la composición o, lo que se salvaguarda es más grave, de mudar la naturaleza del depósito a que pertenece (art. 168.1 CE). El pluralismo político es, en definitiva, una constante intangible y resistente a cualquier propósito de dejar fuera de juego su excelencia jurídica y su eficacia social.

\section{Eficacia del Derecho en el Estado social y democrático que se le somete}

Un Derecho eficaz tiene que confesar sinceramente, si es del caso, su arrepentimiento y mostrar su irreversible voluntad de romper con un pasado juridicopolítico que ha combatido y arruinado los valores inspiradores de una sana idea del ordenamiento jurídico. Hay una gama de actitudes y reacciones que oscilan entre la proscripción radical de ese pasado - cuya memoria trata de abolirse (art. 1.2 LFB) - y el reconocimiento o conversión de sus efectos útiles o asimilables. Las técnicas de depuración del ordenamiento jurídico han manejado el concepto de inconstitucionalidad sobrevenida o inadecuación constitucional del que dio en llamarse Derecho previgente, para conservar ciertas normas y soluciones jurídicas que, gracias a una operación de salvamento, pueden y deben declararse subsistentes (DD $3 \mathrm{CE}$ ). El compromiso - un tanto impenetrable y esotérico- de constituir una sociedad democrática avanzada (dec. 5 Pr. CE) pretende, entre otros objetivos, superar los obstáculos debidos al funcionamiento rutinario de las instituciones, 
acrecentar la movilidad y la libertad de los grupos sociales, y denunciar los malos usos, las posturas equívocas y la insinceridad de los profesionales de la política (arts. 6 y $9.2 \mathrm{CE}$ ).

La eficacia del Derecho se beneficia también del cúmulo de acciones y reacciones que, llegado el momento, hay que iniciar frente a los enemigos de la libertad que, para lograr sus objetivos, se proponen - usando comúnmente de formas desatemperadas - que el Estado social y democrático de Derecho ponga a su alcance, en grado desmedido, cuantas garantías les permitan jugar con ventaja. El Estado no accede, unas veces, a otorgar facilidades excesivas - entendiendo que un sano criterio de defensa social prohíbe rebasar los límites que la tienen en cuenta- y, otras, estima que la actitud positivamente democrática - químicamente pura, se diría- consiste en conceder dicha oportunidad de modo generoso y aun, si se quiere, aventurista y arriesgado. Frente a estos eventuales abusos, se alzan la exigencia de democraticidad interior y exterior de los partidos políticos, los sindicatos y las organizaciones profesionales (arts. 6, 7, 36 y 52 CE); la interdicción de las sociedades secretas o de carácter paramilitar (art. 22.5 CE), de los Tribunales de Honor en la esfera de la administración civil y las organizaciones profesionales (art. $26 \mathrm{CE}$ ), y de los Tribunales de Excepción (art. 117.6 CE); la suspensión de ciertos derechos y libertades con motivo de las investigaciones provocadas por actos terroristas (art. 55.2 $\mathrm{CE}$ ), y el establecimiento de las variantes de los estados de emergencia (art. 116.1 CE). Aun así, la moda del garantismo determina que, no obstante la juricidad de las previsiones tendentes a impedir o moderar las iniciativas de los enemigos de la libertad, se cuide de advertir de las responsabilidades que pueden contraerse si, al reprimirse la vulneración de los derechos y libertades constitucionales, se pervierten los mecanismos de control destinados a defender unos y otras (arts. 55.2 II y 116.6 CE).

El Estado social y democrático de Derecho - cuyas obras se inscriben en este contexto- conserva su cualidad de tal gracias a dos notas que aseguran la eficacia de las normas del ordenamiento jurídico. La primera consiste en que los poderes públicos están sujetos a los principios y/o preceptos constitucionales, y al resto de dicho ordenamiento (art. 9.1 CE), pues el legislador ha de atenerse, bajo sanción de nulidad, a las orientaciones y pautas de la legalidad fundamental (arts. 53.1 y 161.1 a CE), las Administraciones Públicas, plenamente sometidas a la ley y al Derecho, soportan el control jurisdiccional de sus actividades (arts. 103.1 y 106.1 CE), y los órganos jurisdiccionales están únicamente sometidos al imperio de la ley (art. 112.1 CE). Tal sujeción coincide con la que obliga a los particulares (art. 9.1 CE) y difiere de la 
postura peculiar de algunos poderes de hecho que, como los partidos políticos y los sindicatos crean su propio ordenamiento jurídico y se obligan a no invadir y a respetar el campo de esas normas (arts. 6 y 7 $\mathrm{CE}$ ). Otra garantía de la eficacia del Derecho es la generalización del control judicial que cobra especial importancia si la efectiva tutela de los derechos subjetivos e intereses legítimos de todas las personas se promueve al rango de un derecho fundamental (art. 24.1 CE) que, además de la protección de la jurisdicción ordinaria, incluye la emanada de la justicia constitucional (art. 161.1 CE), y reposa en la sólida idea de que la unidad de jurisdicción equivale al reflejo que, en el campo procesal, tiene la unidad de soberanía (art. 117.5 CE). El Derecho deseablemente eficaz es la suma de sectores del ordenamiento jurídico que comprenden, la legislación en sentido material o vertical -integrante del llamado bloque de constitucionalidad y que deriva desde el ápice constitucional hasta la norma escrita más modesta- y las fuentes secundarias cuyo juego impide alegar la existencia de lagunas del Derecho ( $\$ 8$ EMTPC.c. y art. 1.1 C.c.). La ley, en el amplio sentido que se indica, y las fuentes secundarias se perfeccionan gracias a las acciones cuasinormativas de las tareas complementarias de la justicia constitucional y de la jurisprudencia ordinaria (arts. 1.4 C.c. y 5.1 LOPJ). Este afán de eficacia se cualifica y acrecienta con la preponderancia de otros ordenamientos supranacionales - que priman sobre el Derecho estatal- y con la atribución a los tratados internacionales de una categoría superior a la de las leyes con las que conviven en el ámbito interno de la soberanía del Estado receptor (arts. 96.1 CE y 1.5 C.c.).

La eficacia de la ley presupone la plenitud de inmunidad que, a primera vista, resulta de su elaboración por la asamblea parlamentaria que refleja la voluntad popular (arts. 1.2 y 66.1 y $2 \mathrm{CE}$ ). El principio de unidad jurisdiccional obsta al ejercicio de la competencia paralela de las Administraciones Públicas (arts. 106.1 y 117.4 CE) y justifica la innovación de un orden judicial llamado a conocer de esas materias (arts. 117.5, 106.1 CE y 9.4 LOPJ). El establecimiento de una justicia constitucional satisface la necesidad de defender la legalidad fundamental y, además, reduce, normaliza o liquida las disfunciones resultantes de la estructura regional o autonómica del Estado compuesto (art. 161.1 a y $c$, y 2 CE).

Procede reiterar la apreciación —a que lleva el análisis fenomenológico de sus episodios- de la tendencia a acrecentar las competencias específicas de un sistema de justicia constitucional que, junto al ejercicio de sus atribuciones naturales, ensaya controles atípicos de la actividad de la jurisdicción ordinaria e invade el espacio de la legislación, preventivamente - si adelanta y trata de imponer su propio parecer so- 
bre el desarrollo de ciertos principios y/o preceptos constitucionaleso terapéuticamente, si, en otras hipótesis, desborda los límites del papel del legislador negativo - que expulsa los contenidos inconstitucionales de las zonas del ordenamiento jurídico viciadas de esa antijuricidady se comporta como legislador positivo. Cualidad, ésta, que no se predica de su contraria en el sentido clásico de la dicotomía Derecho $\mathrm{Na}$ tural innato y Derecho Positivo que brota del esfuerzo del legislador, sino en la acepción de una fuente que, en vez de empequeñecer y restar, añade al ordenamiento jurídico los ingredientes de que hasta entonces carecía. La justicia constitucional ejercita su poder negativo a través de principios que, bajo apariencia de simples complementos de la legalidad aplicada, devienen normas jurídicas independientes de ella y dotadas de carácter principal. El autocontrol de la justicia constitucional cierra el cuerpo de garantías de la eficacia de un Derecho cuya aplicación debe ser, al unísono, templada y expansiva.

\section{Equilibrio y separación de poderes como condiciones de la eficacia del Derecho}

Las normas constitucionales suelen denominar poderes públicos a los centros de que, merced a la correspondiente delación de competencias, emanan, en su más amplio sentido, decisiones que atañen caracterizadamente a la causa del interés general o, por mejor decir, a los requerimientos procedentes de cada círculo de intereses generales (arts. $30.3,44.2,103.1,128.1$ y $155.1 \mathrm{CE})$. La noción relativamente determinada de poderes públicos se completa con la de poderes sociales o poderes de hecho, que rotula el inventario formado por los actores notables de la vida común de relación o por los grupos significativos que componen la sociedad pluralista (arts. 6, 7, 9.2 y 20.2 CE). Más exacto que hablar de separación de poderes, es evaluar la eficacia del Derecho a través de la intervención de los agentes públicos que asumen la dirección del Estado, el gobierno y la representación parlamentaria.

El Estado en que concurren estas circunstancias, presenta unos rasgos que explican y convencen de la eficacia del Derecho generado y aplicado en su ámbito. El Estado que surge del acto de su constitución, ofrece una estructura - todo lo contrario de lo coyuntural o lo episódico- que da fe de la continuidad y permanencia con que satisface sus fines por medio de un ordenamiento jurídico que pone su voluntad al servicio de las necesidades en cuestión. La institucionalización del Estado resulta de que, ante lo insufrible e ingrato de un diseño de fuerzas sociales en que la persona individual oprime a las demás personas físi- 
cas, es más sugestivo y aceptable que dicha sumisión se establezca respecto de una persona jurídica que ejercita su autoridad por medio del Derecho eficaz al que se subordina y cuyas normas prefiguran sus modos de acción. A ello no obsta el rechazo que provocó de antiguo la reducción conceptual del Estado a la morfología de una persona colectiva, que los sistemas autoritarios llevaron a sus extremos más penosos. El triunfo del Derecho implica, que el poder anida en una entidad abstracta - sede de emplazamiento de los poderes públicos- cuyos componentes son el Gobierno y la representación popular (arts. 66.1 y 92 $\mathrm{CE})$. El pueblo es el titular originario del poder político, el Estado es el titular derivativo - que crea el Derecho eficaz y queda sometido a ély los gobernantes asumen su ejercicio. La solidez del Estado social y democrático de Derecho descansa en la idea de que la más alta dirección avala la unidad y permanencia (art. 56.1 CE) que, en las monarquías hereditarias asegura la continuidad, lleva consigo inherente a una suerte de posesión civilísima que se da en esos casos (art. 57.1 CE).

El Estado de Derecho resulta de un proceso de organización debido, entre otros elementos, a la eficacia del sistema de normas que integran el ordenamiento jurídico, porque la dimensión de los diferentes sectores del mismo constituye el medio de lograr el sustento racional de aquél y perfeccionar el objetivo consistente en la promoción del bien común.

Una orientación optimista sostiene que, gracias a esta perspectiva, el desarrollo de la organización social y administrativa del Estado presupone que la autoridad se funda en la racionalidad de la empresa y en el convencimiento de que hay que respetar escrupulosamente esos mecanismos y el ejercicio del poder que les es consustancial. La concepción pesimista considera, que sólo a partir de las disfunciones que dicha estructura registra, se agota su diagnóstico y se cuenta con la experiencia necesaria para efectuar correcciones que no datan de iniciativas químicamente puras y sí de la constancia de los errores advertidos.

El origen racional del Estado deriva de su constitución en virtud de un Derecho cuya eficacia depende de un principio productivo de división del trabajo - encarnado en la separación de poderes- y un proceso de centralización al que el Derecho presta su parte de razón y que, con el tiempo, se flexibiliza mediante fórmulas o soluciones de evidente eficacia social (arts. 2 y $143.1 \mathrm{CE}$ ). La división del trabajo determina que, como atributo complementario de racionalidad, el $D e$ recho del Estado tenga una existencia separada del Derecho de la comunidad militar (art. $8 \mathrm{CE}$ ) y del ordenamiento religioso (art. $16 \mathrm{CE}$ ).

La perfección tecnicojurídica de la estructura de los poderes públicos garantiza el cumplimiento de sus obligaciones de sujeción al Dere- 
cho y evita la arbitrariedad de las decisiones dirigidas a los destinatarios del ejercicio de sus competencias.

El equilibrio de los poderes públicos defiende frente a las agresiones de la fuerza incontrolada que irrumpe si falta el mínimo de coordinación que debe existir entre los mismos. Su disponibilidad - consecuente con la naturaleza de los poderes-función que se les otorgan para facilitar el cumplimiento de las cargas impuestas - significa que sus prestaciones han de ser accesibles a cuantos precisan de su contribución satisfactoria.

Conviene recordar que, andando el tiempo, se ha esperado y exigido de los poderes públicos una acción transformadora inherente a los objetivos de socialización del Derecho, y que uno de sus postulados ha sostenido que las necesidades y valores sociales primaban, absolutamente y sin reservas, sobre los condicionamientos económicos de las soluciones admisibles. De ahí la peligrosa deformación de principios en pro de la tesis maximalista, según la cual las acciones de los protagonistas y racionalizadores económicos representan un impedimento para la socialización y el engrandecimiento moral de las soluciones jurídicas, lo que, a la vez, fomenta la denuncia de la imagen demoniaca de la Economía, asociada, con progresiva intensidad, a cuantas iniciativas y ensayos reconocían esa procedencia. Ni siquiera faltan consideraciones teológicas que han descubierto en ello los resortes y reflejos del fenómeno de la encarnación del mal.

Las circunstancias de hoy - en que no pocas de las soluciones del Derecho se deben a las repercusiones y avatares de la crisis económi$\mathrm{ca}$ - han obligado a revisar y revocar, en su caso, las propuestas más intransigentes de esa manera de pensar. Ha perdido todo su dogmatismo la idea de que las vías de consecución de la justicia social pugnan con la racionalización económica, y el mito de la destrucción absoluta de ciertos presupuestos - económicos también- que, lejos de ser incompatibles con ella, promueven y facilitan el buen fin de sus aspiraciones. El esfuerzo de transformación — volcado en la busca de la efectividad de un Derecho objetivo que se compromete, romántica y unilateralmente, con la causa de la justicia y el progreso sociales- no tiene sentido, tal y como actualmente son las cosas, si no se aceptan la necesidad y utilidad de racionalizar económicamente dichos objetivos, y de reconocer que, sin este soporte, son muy escasas sus oportunidades de prevalecer.

No hay que olvidar que, al contemplar el panorama de las mejoras y adelantos sociales perseguidos por el Derecho efectivo, la vieja idea utilitarista del orden natural dependía de una reflexión semejante a la que procede hacer aquí y ahora. Las reformas sociales de entonces de 
ilustración elemental que precedía y acompañaba a su ejecución. La excelencia de lo justo - que hoy consta y se vierte en la idea de efectividad del Derecho - consistía en dar entrada y audiencia a los requerimientos de unas necesidades patentes e inmediatas, y no en simular, con el mejor y menos atinado de los propósitos pensables, cuestiones irrelevantes o infrecuentes, cuya insuficiencia existencial caía de su peso.

Las circunstancias de prosperidad - conexas con los adelantos tecnológicos, derivados de las adaptaciones postbélicas, y con la subsistencia de los aprovechamientos coloniales - que asistieron al nacimiento del Estado Social de Derecho, explicaban por qué el éxito de las reformas sociales sólo dependía de la dosis de voluntad política de unos poderes públicos cuyos recursos económicos eran abundantes. La política social no suscitaba contradicciones con una política económica que discurría por cauces extraños al planteamiento de problemas insuperables y aplicaba unas reglas de las que la conciencia cultural no discrepaba lo más mínimo.

Tan pronto como la Economía registra situaciones críticas debidas a las dificultades de productividad, al aumento de la contestación social y al control de aprovisionamiento de los procesos productivos, las reformas de monta, auspiciadas por los poderes públicos, se someten a un ritmo de moderación y sólo si previamente están resueltos los arduos problemas de política económica que les son inherentes. Las modernas reacciones constitucionales se sensibilizan a este dato y conectan las aspiraciones de la política social con lo inexcusable de una política económica cuyas previsiones exactas y buenos resultados condicionan la ejecución y el éxito de la primera de ambas (cap. 3. ${ }^{\circ}$, tít. $1 \mathrm{CE}$ ).

La excelencia de la vida social —en que se traduce, hoy por hoy, el modo de existir justamente en cualquier comunidad - se hace inviable o muy difícil, si el Derecho - cuya efectividad va en pos de ese objetivo- no cuenta con el referente tranquilizador de haberse despejado las incógnitas a que dan lugar los desafíos de la Economía. Lo económico impone limitaciones, porque se opera en un ámbito de reparto e insuficiencia de recursos, y porque las soluciones técnicas de la Economía condicionan el éxito del esfuerzo de transformación y, en definitiva, la efectividad del Derecho que se ha comprometido con él.

La sustitución de un Derecho eficaz de preceptos por un Derecho efectivo de principios —útil para que los poderes públicos exijan la parte de contribución social correspondiente al ejercicio de las libertades económicas - restauraría la esperanza puesta en ese Derecho Común que siempre se ha preciado de pertenecer a las mejores tradiciones de las sociedades avanzadas. 


\section{Abreviaturas y siglas}

art. artículo.

cap. capítulo.

C.c. Código Civil español de 24.7.(8)89.

CE Constitución española de 27.12.78.

CN Constitución norteamericana de 17.5.(7)87.

CI Constitución italiana de 27.12.47.

CM Constitución mejicana de 16.9.17.

DDHC Declaración de los derechos del hombre y del ciudadano de 5.10.(7)89.

dec. decisión.

EMTPC.c. Exposición de Motivos de la L. 31.5.74, de reforma del Título Preliminar del Código Civil.

LFB Ley Fundamental de Bonn de 8.5.49.

LOPJ Ley Orgánica del Poder Judicial de 1.7.85.

n. ${ }^{\circ} \quad$ número.

Pr. Preámbulo.

sec. sección.

tít. título. 